\title{
Reduced soluble TNF-like weak inducer of apoptosis (sTWEAK) and increased frap in postmenopausal women with metabolic syndrome
}

\author{
Fabio Vasconcellos Comim*, Etiane Tatsch, Bruna Hausen, Juliana Wispel, Leo Canterle Dal Osto, \\ Rizzi Adhan de Viera, Paola Roehrs Colpo, Pietra Zorzo, Lucas Venturini Zottele, Karen Koff da Costa, \\ Rafael Noal Moresco, Melissa Orlandin Premaor
}

From 20th Brazilian Diabetes Society Congress

Porto Alegre, Brazil. 11-18 November 2015

\section{Background}

Recent evidence in the literature has reported the association between the soluble bioactive form of TNF-like weak inducer of apoptosis (sTWEAK) to insulin resistance, type 2 DM, chronic kidney disease, and atherosclerosis. To date, just a single study has evaluated this novel inflammatory cytokine in Metabolic Syndrome (MetS), showing a reduction in the circulating levels of sTWEAK in elder Caucasian patients ( $>97 \%$ hypertensive) at high cardiovascular risk. Nevertheless, is not known whether individuals from a mixed population at the primary care may exhibit or not similar changes.

\section{Objectives}

The aims of this study were to investigate the association between MetS and biomarkers of chronic inflammation (plasma sTWEAK) and oxidative stress (AOPP, Nox, FRAP) in postmenopausal women recruited at community level.

\section{Materials and methods}

This cross-sectional analysis enrolled 157 women from a previous community-based study of 1057 postmenopausal women covering all basic health units from the municipality of Santa Maria-RS. Participants answered a questionnaire including the clinical history and co-morbidities and were submitted to anthropometric evaluation (height, weight, abdominal circumference), measurement of blood pressure and blood sample collection. Plasma levels of sTWEAK were assessed by ELISA. Biochemical analysis (glucose, LDL, HDL, triglycerides) and oxidative stress markers (AOPP, Nox and FRAP) were determined in serum as previously described. The definition of MetS was based by established criteria of the International Diabetes Federation (IDF). This study was approved by the local Ethics Committee. Assimetric data was $\log \mathrm{N}$ transformed. The significance level was set at $\mathrm{P}<0.05$.

\section{Results}

No differences in age were observed between postmenopausal women of non-MetS $(n=42)$ and MetS $(n=115)$ groups. The (mean $+\mathrm{SD})$ of age was, respectively, $66.6+$ $7 \mathrm{y}$ and $68.6+6 \mathrm{y}$ in non-MetS and MetS. The diagnosis of hypertension was present in $17 \%$ of non-MetS and $85 \%$ of MetS women. Interestingly, FRAP levels were significantly higher in MetS $(522.6+296 \mu \mathrm{mol} / \mathrm{L})$ against non-MetS $(411.1+221 \mu \mathrm{mol} / \mathrm{L})(\mathrm{p}=0.02)$. sTWEAK in plasma was reduced in MetS $(282.9+158 \mathrm{pg} / \mathrm{mL})$ versus non-MetS $(338.3+162 \mathrm{pg} / \mathrm{mL})$ and reach significance after $\log \mathrm{N}$ transformation $(\mathrm{p}=0.027)$.

\section{Conclusion}

Our Results supports for the first time a disruption of (sTWEAK) and oxidative stress marker (FRAP) in postmenopausal women with MetS in a mixed population obtained from a community-based study.

* Correspondence: fabio.comim@ufsm.br

Universidade Federal de Santa Maria, Santa Maria, Brazil 
- Convenient online submission

- Thorough peer review

- No space constraints or color figure charges

- Immediate publication on acceptance

- Inclusion in PubMed, CAS, Scopus and Google Scholar

- Research which is freely available for redistribution 